\title{
Una aproximación al golpe de Estado de 1930 desde el rol asumido por algunos de sus protagonistas
}

An approach to the coup d'état of 1930 from the role assumed by some of its protagonists.

Diego Abel Sánchez

DOI: https://doi.org/10.24215/2314257Xe114

Universidad Nacional de Tres de Febrero, Argentina

profesordehistoria@hotmail.com.ar

Recepción: 01 Diciembre 2019

Aprobación: 20 Abril 2020

\section{Resumen:}

Los golpes de Estado han despertado siempre el interés de un amplio espectro de politólogos e historiadores por su alto impacto en la política nacional. A pesar de ello, el presente artículo pretende arrojar luces sobre temas y cuestiones algo descuidados por las producciones historiografías recientes, haciendo hincapié no sólo en algunas particularidades de la gestación y ejecución del golpe de Estado de 1930 ocurrido en la Argentina, sino además en aspectos vinculados con el liderazgo militar ejercido por el general Uriburu y su Estado Mayor Revolucionario. Se busca aportar una visión particular y diferenciada del tema en cuestión, desde la óptica y rol asumido por sus principales protagonistas - mayormente militares-. Las fuentes consultadas y analizadas fueron variadas, pero se han priorizado los documentos existentes en el Fondo Documental de José Félix Uriburu ubicado en el Archivo General de la Nación. Entre las conclusiones a las que se arribó no debe soslayarse el destacado y criticado rol asumido por los tenientes coroneles Álvaro Alsogaray y Bautista Molina durante la conspiración septembrista, como así también durante el gobierno presidido por el general Uriburu hasta 1932.

Palabras Clave: Nacionalismo, Corporativismo, Revolución, Uriburu, Justo.

\begin{abstract}
:
Coups d'etat have always aroused the interest of a broad spectrum of political scientists and historians because of their high impact on national politics. Despite this, this article aims to shed light on issues somewhat neglected by the recent historiography productions, emphasizing not only some particularities of the gestation and execution of the coup d'état of 1930 occurred in Argentina, but also in aspects linked to the leadership exercised by General Uriburu and his Revolutionary Staff. The aim is to provide a particular and differentiated vision of the subject in question, from the perspective and role assumed by its main protagonists - majorly military-. The sources consulted and analyzed were varied, but the existing documents in the Documentary Fund of José Félix Uriburu existing in the General Archive of the Nation have been prioritized. Among the conclusions that were reached should not be ignored the prominent and criticized role assumed by the lieutenant colonels Álvaro Alsogaray and Bautista Molina during the Septembrist conspiracy as well as during the government presided by General Uriburu until 1932.
\end{abstract}

KEYWORDS: Nationalism, Corporatism, Revolution, Uriburu, Justo.

\section{INTRODUCCIÓN}

La relevancia del golpe de Estado de 1930 debe medirse, en primer lugar, por su carácter original, ya que carece de antecedentes en la historia política argentina, y por haber iniciado un período de inestabilidad política creciente que afectó al país en las próximas décadas (Rouquié, 1985). El 6 de septiembre no sólo respondió a la crisis política y económica del país, sino que marcó además el fin de la alternancia de setenta años de presidentes constitucionales y de una tradición de abstención política del Ejército que había perdurado por veinticinco años.

Para la redacción del presente artículo se ha trabajado con fuentes existentes en el Fondo Documental de J. F. Uriburu del Archivo General de la Nación -en adelante: AGN/FJFU-, también se consultaron revistas militares de la Biblioteca del Círculo Militar -BCM- y el legajo personal del general José Félix Uriburu en el Archivo Histórico del Ejército. Se examinaron las particularidades que revistió la ejecución del 
golpe de Estado, reconstruyendo las dificultades que tuvieron los militares golpistas aquel 6 de septiembre de 1930. Estas contrariedades se evidenciaron en primer lugar en el reclutamiento de oficiales y luego en la movilización de las tropas. Un claro ejemplo de ello fueron los radiotelegramas intercambiados entre los generales Álvarez y Uriburu, donde se anticipó la negativa de unidades de Campo de Mayo a participar del levantamiento septembrista. ${ }^{1}$ Por otro lado el estudio detallado de las circulares permite entrever no sólo las tensiones, sino además los obstáculos que existieron antes, durante y después del golpe de Estado (Potash, 1985).

Las producciones que abordaron estas cuestiones se realizaron desde enfoques algo sesgados o con miradas demasiado panorámicas. Resulta destacable que este tema no ha sido retomado desde la historiografía reciente y conjuntamente se tendió a exaltar la relevancia exclusiva del general José Félix Uriburu y de su proyecto corporativista (Dalmazzo, 2010; Finchelstein, 2002), a poner el foco en los antecedentes políticos o económicos de dicho acontecimiento (Etchepareborda, 1958; Rock, 1992) o a encuadrarlo mayormente a aspectos de índole castrense (Orona, 1966; Scenna, 1980). En este artículo se indagará este acontecimiento desde el rol asumido por algunos civiles y militares, contemplando para ello las complejas relaciones sociales y los intereses en conflicto que se pusieron de manifiesto en las instancias preliminares como así también a lo largo de aquella jornada. ${ }^{2}$ Una rica y extensa bibliografía ha buscado brindar explicaciones generales al primer golpe de Estado en la historia argentina, subrayando -como se anticipó- la importancia del contexto social y económico, la emergencia del nacionalismo y la crisis de la democracia liberal. Este artículo propone colaborar con la comprensión de este destacado acontecimiento desde caminos alternativos enfocados desde la óptica y visión de sus máximos protagonistas - mayormente militares integrantes del denominado Estado Mayor Revolucionario-.

\section{LA CONSPIRACIÓN Y SU CONTEXTO}

El golpe de Estado, a nivel local, fue el resultado de una serie de conversaciones ${ }^{3}$ y esfuerzos organizativos que se extendieron aproximadamente por tres meses y que se tradujeron en una acción improvisada y de último momento. Los niveles de apoyo a la figura y gobierno de Yrigoyen comenzaron a declinar debido, en buena medida, a las presiones políticas que surgieron como consecuencia de la Gran Depresión. En este contexto, La Nueva República dejó de publicarse en razón de que Juan Carulla ${ }^{4}$ y los demás miembros del grupo editor se concentraron en la organización de una fuerza paramilitar: La Liga Republicana. Esta organización llegó a contar con más de tres mil integrantes que se enfrentaban no sólo por el control de las calles con el Klan Radical -un grupo oficialista de similares características- sino que tenían por objetivo último actuar en pos de derrocar al gobierno (Rock, 1992).

El alzamiento septembrista de 1930 se caracterizó además por la convergencia de varios factores, algunos de ellos externos, imbuidos en un contexto de carácter más global y complejo. En él confluían el impacto de la crisis de 1929, el temor a la expansión del socialismo y la influencia creciente de pensadores nacionalistas y conservadores católicos (algunos de ellos del siglo pasado y retomados en este nuevo escenario). Las concepciones de estos autores (reproducidas en publicaciones locales ${ }^{5}$ ) eran en gran medida extremistas, como lo fueron Joseph De Maistre, Gustave de Bonald, Maurice Barrés, Juan Donoso Cortés, Marcelino Menendéz Pelayo o Charles Maurras. En este marco se agudizaron en la región las críticas contra el liberalismo tanto en su carácter económico como en el político. Además de la irrupción de la Gran Depresión, el desencanto generalizado respecto de la economía liberal y de los regímenes democráticos operaron como sólidos argumentos para justificar el accionar de agrupaciones de extrema derecha que adoptaron modalidades particulares en cada país, definiendo claros vínculos diferenciados entre gobierno, partidos políticos, Ejército e iglesia (McGee Deutsch, 2005). ${ }^{6}$ 
Muchos de los nacionalistas del país que pertenecían a una misma extracción social se sumaron primero a la causa antiyrigoyenista y luego al objetivo golpista, utilizando estas publicaciones para difundir sus ideales opositores y destituyentes. Pero esta acción, como señala María Inés Tato (2004), la ejecutaban desde un mismo conglomerado de derecha pero con diferentes tendencias ideológicas. Un claro ejemplo de ello fue Francisco Uriburu, que nunca dejó de creer en el sistema de partidos políticos, logrando durante el gobierno de Justo (fraude imperante) una banca de diputado por el Partido Conservador Bonaerense.

A pesar de la existencia de estas agrupaciones, no se daban las condiciones para la reproducción de los modelos extremistas europeos, ya que este movimiento de derecha a pesar de algunos esfuerzos aislados nunca se unió y fortaleció en un frente social único y masivo bajo los parámetros ideológicos de los modelos autoritarios y antiliberales presentes en el viejo continente. En este sentido, y desde una mirada más amplia, cabe aclarar que la región no escapó a la influencia del fascismo, del falangismo o del maurrasismo, ni pudo evitar el impacto de importantes acontecimientos ocurridos a comienzo del siglo XX (conflictos armados globales, revoluciones, crisis financieras, guerras civiles, etc.). Es en este marco particular y convulsionado donde proliferaron agrupaciones de extrema derecha. En Chile su accionar se remonta a 1910 (con rebrotes en 1918 y 1925) en las provincias de Tarapacá y Antofagasta donde se formaron Ligas Patrióticas Militares -extendiéndose luego por todo el país- con activa participación de civiles y militares retirados. Estas sobresalieron por su agresividad xenofóbica hacia la comunidad peruana y boliviana residentes en el país, apoyándose además en publicaciones tales como El Ajicito, El Corvo, El Roto Chileno, El Eco Patrio, entre otras. Estas agrupaciones incluso generaron intercambios y encuentros concretos con la Liga Patriótica Argentina, como señaló el diario El Mercurio en sus publicaciones del 27/8/1920, 25/1/1921 y 28/7/1922, coincidiendo incluso en sus objetivos y accionar masacrando obreros en huelga (Miranda, González Prieto, y McGee Deutsch, 1993).

En contraposición a esta realidad política emergieron también en la región fuerzas que se opusieron al devenir de estas tendencias antidemocráticas, pero sosteniendo cierto carácter antiimperialista y estatista. Alternativas progresistas emergieron con nitidez y contundencia en Perú y México, entre otros países, irradiando su pensamiento crítico y propuestas superadoras por el continente. En cuanto al aprismo, el linaje reformista aseguraba la participación de varios de sus dirigentes en los circuitos intelectuales y políticos argentinos (la presencia de exiliados apristas en Buenos Aires y La Plata contribuyó a afianzar la relación). El cardenismo, por su parte, fue atendido luego por FORJA e incluso por sectores más integrados en el aparato partidario de la UCR (Cattaruzza, 2016). El yrigoyenismo se inscribió en este marco particular, y si bien adoptó características propias en el país, excedió las fronteras nacionales nutriéndose de otras expresiones y tendencias, evitando apelar desde un posicionamiento izquierdista a consignas internacionalistas, al punto de reprimir duramente huelgas obreras y no predicar la lucha de clases. Ante estas limitaciones, las críticas y propuestas del nacionalismo foráneo emergieron desde un tono elitista, antidemocrático, o en algunos casos desde reminiscencias algo nostálgicas y conservadoras. En otros casos -como ya se señaló- se recurrió directamente a la violencia y la agresividad callejera, ejecutada desde organizaciones parapoliciales (toleradas por el gobierno) como la Liga Patriótica Argentina y La Legión Cívica, entre otras.

A nivel local estas agrupaciones prestaron tempranamente su colaboración y apoyo entusiasta a la causa golpista, pero para llevar adelante sus objetivos de manera exitosa el general J. F. Uriburu debía contar primeramente con el apoyo extensivo de las fuerzas armadas (principalmente del Ejército) y en menor medida lograr un necesario acompañamiento de la prensa junto a cierto aval de la población civil. ${ }^{7}$ Si bien su figura despertaba adhesiones en algunos círculos del conservadorismo (Botana, 1977), su base de apoyo civil se limitaba en particular a sectores minoritarios representativos de la elite tradicional. El general Uriburu afirmaba, en un discurso dado el 7 de julio de 1931, que la autodefinida Revolución había sido inspirada y ejecutada por el Ejército y la Marina, negando o desestimando así cualquier participación civil destacada. Por ello, José Félix Uriburu, declaraba que su compromiso era primeramente hacia las FF. AA. y que la Revolución había sido realizada no sólo para derrocar un gobierno sino contra un sistema, para implantar un régimen 
orgánico que garantizara orden y equilibrio. Demostraba así sus verdaderas intenciones y ambiciones, dejando en el olvido las promesas de legalidad, apertura política y respeto constitucional (Halperin Donghi, 2004).

Según afirmaciones del teniente coronel Álvaro Alsogaray, en el contexto de una de las tantas reuniones conspirativas contra el gobierno radical, se intervino sobre el Dr. Alberto Uriburu (por la influencia que este tenía sobre las decisiones de su padre). Ante las dudas manifiestas por el hijo del general sobre la falta de cohesión y unidad entre los militares presentes, se le garantizó que a su padre no se lo llevaría a liderar una chirinada. ${ }^{8}$ Contrario a estas afirmaciones, el joven oficial Juan Domingo Perón manifestaba que si el general Uriburu se lanzaba a la calle con algún núcleo de fuerzas, que difícilmente pudiera conseguir, y el pueblo simultáneamente no se largaba a la calle, este sería un espectáculo grotesco condenado a la derrota segura. En este sentido, Feldman aclara que existían diferentes concepciones de pueblo reflejadas en la prensa, desde titulares acompañados por grandes fotografías del mismo día del estallido golpista. Todas estas imágenes eran acompañadas de elocuentes titulares como los del diario Crítica del día 7 de septiembre: "El pueblo en las calles ha colaborado con el triunfo", "Toda la población ha participado de la gran jornada”; los del día 8 de septiembre: "Militares y civiles todos unidos", o los del día 9 de setiembre: "En El Palomar, los soldados y el pueblo". P Para el autor existía el denominado "pueblo auténtico", identificado con los sectores abiertamente anti-yrigoyenistas y el populacho de tendencia yrigoyenista. Señala además -en coincidencia con otros autores- que una muchedumbre de hombres, mujeres y niños fueron arrastrados por una marea callejera inmersa en un ambiente revolucionario que se había instalado en las calles (Feldman, 2008). ${ }^{10}$

Entre otros motivos que sirvieron de argumento sólido para que el estallido golpista tomara forma definitiva, se puede destacar que las Fuerzas Armadas - en general- y el Ejército -en particular-, sintiéndose avasallados, ignorados y desprestigiados por el gobierno de Yrigoyen, resultaron permeables ante la creciente y profunda campaña de oposición anti-Yrigoyenista. Así la prensa opositora adoptó un destacado rol desestabilizante encontrando un importante eco entre las filas de las FF. AA. ${ }^{11}$

Una de las cuestiones que incidieron en la posibilidad de una conspiración es que se partió del convencimiento pleno - pero errado- de que la UCR era imbatible en las urnas. Esta invencibilidad electoral encontró algunos escollos hacia 1930 en las elecciones legislativas de marzo, y lejos de alejar el ímpetu golpista lo potenció, alimentando además disidencias internas dentro del mismo gobierno y del partido radical. Este nuevo escenario político colaboró indirectamente con las tramas externas ya consolidadas y definidas, debilitando al partido gobernante en su propio seno. A partir de los enfrentamientos derivados de la búsqueda de culpables y responsables de la derrota en Capital Federal en manos del socialismo, se generaron diferencias y confrontaciones dentro de la UCR.

El posterior retiro de José F. Uriburu del Ejército abrió la alternativa concreta de poder recurrir a su liderazgo -entre otros posibles, como el del general Justo- para encabezar una acción armada contra el gobierno radical, recientemente electo por voto popular. Los complotados, liderados ahora por el general Uriburu, pretendían encarar esta acción no como líderes políticos de una conjura, sino más bien como representantes de una fuerza opositora multisectorial que se manifestaba claramente con objetivos desestabilizantes. ${ }^{12}$ El regreso de Hipólito Yrigoyen en 1928 impactó directamente en los ánimos de la cúpula militar, que contaba con muchos integrantes vinculados a la Logia General San Martín. Este malestar se potenció con la designación del general Luis Dellepiane que, como ministro de Guerra, llevó adelante una serie de purgas que alimentaron los rencores -ya presentes- contra el gobierno. Estos recambios de personal se dieron en una atmósfera colmada de incertidumbre e improvisación. Este clima se vio acompañado además por una actitud de indiferencia y desinterés en las cuestiones de fondo relacionadas con las problemáticas existentes en el seno del Ejército y de todas las FF. AA.

La proclamada "revolución" ${ }^{13}$ debía estallar el día 30 de agosto, y se debía contar con la adhesión de las tropas de Campo de Mayo, El Palomar, San Martín y Liniers, entre otras divisiones del Ejército. Lo cierto es que a esa fecha no se había alcanzado dicho objetivo, cuestión que obligó a su suspensión, provocando en la 
oficialidad comprometida gran desconcierto. Unos días antes, el día 28 de agosto, se sumó a la incertidumbre y dudas reinantes las detenciones de algunos oficiales entre los que se encontraba el coronel José Mayora. Ante estas señales adversas los adherentes al movimiento no declinaron en su activismo conspirativo, a pesar de que las fuerzas con las que se contaba para el mes de septiembre no diferían notoriamente de la situación de agosto (había trascurrido tan sólo una semana). A pesar de no tener claras y contundentes garantías de éxito, los militares y civiles golpistas actuaron con cierta miopía ante una realidad innegable, mostrando un alto grado de improvisación para derribar al gobierno radical.

Aunque no se contaba con la adhesión extensiva de estas unidades militares, se logró el apoyo del Colegio Militar de la Nación -además algunos regimientos, bases de la aviación militar como El Palomar y Paraná, de escasos efectivos de comisarias que fueron anuladas y que se sumaron luego a la columna principal, bomberos y civiles armados-. El entonces coronel Francisco Reynolds - director del Colegio Militar de La Nación- ${ }^{14}$, que acompañó decididamente y a última hora al general Uriburu en el alzamiento golpista de 1930, reafirmaba incluso que el plan, previsto y armado -según su opinión - con esmero durante meses, debió ser abandonado y reemplazado luego por otro. Esta cuestión obedecía a que ya las bases de su poder de acción resultaban erróneas al no contarse con los efectivos previstos, debido a que no se habían sublevado, por lo que el nuevo plan se denominaría “Colegio Militar y apoyo popular". Este aspecto pone en evidencia no sólo el gran nivel de improvisación y premura con el que se actuó, sino que además reafirma el lugar central que ocupó el Colegio Militar en el alzamiento. Se pone en evidencia además el forzado acompañamiento de civiles, mayormente armados (a los que se le entregaron aproximadamente 500 armas - pistolas y fusiles- bajo recibo, muchas de las cuales nunca se recuperaron), por la debilidad evidente que adoptaba el movimiento.

$\mathrm{Al}$ tomar el coronel Reynolds pleno conocimiento de las acciones que se estaban desarrollando en la noche del 5 de septiembre, se sucedieron episodios que pusieron en duda su participación protagónica y por ende el de la institución que él comandaba. Se había verificado que la mayoría de los oficiales del Colegio Militar de la Nación no se plegaban al movimiento, el subdirector teniente coronel Alberto Lynch no lo acompañaba y había retirado a su hijo - cadete del colegio militar- para que no participe del alzamiento. Los oficiales Alfredo Baisi y Puente Pistarini llegaban de Campo de Mayo con noticias que eran desalentadoras, al igual que las informaciones que arribaban de la base militar de El Palomar. Ante esta innegable realidad, las alternativas que se presentaban eran: permanecer leal al desprestigiado gobierno radical encabezado por el vicepresidente Martínez, o marchar contra él y "jugarse con todo" por el triunfo de un alzamiento, de resultado incierto, liderado por sus "cadetes de la gloria”. Esta última opción prevaleció, según sus palabras y alegando cuestiones muy personales, debido a que el gobierno había defraudado al país, a las Fuerzas Armadas, a sus correligionarios y amigos políticos (Potash, 1985, p. 26). Sus bisoños cadetes, formados bajo la dura disciplina de obediencia prusiana, respondieron sin dudar al llamamiento de su jefe el coronel Reynolds (Potash, 1985, p. 80) que a las 0:55 del día 6 de septiembre ${ }^{15}$ de 1930 se pronunció por la revolución. ${ }^{16}$

El movimiento de tropas se mostraba dubitativo y debilitado; existía incluso la posibilidad de paralización del mismo, lo que incrementó el pesimismo castrense. Siendo las 9 h, desde Campo de Mayo el general Álvarez intentó ponerse en contacto con aviadores que habían arrojado proclamas revolucionarias. La respuesta del capitán aviador militar Pedro Castex fue que estaba subordinado al general J. F. Uriburu y que esperaba órdenes para bombardear Campo de Mayo. Se intercedió sobre dicho oficial para que no procediera, dirigiéndose luego al encuentro con Uriburu en el Colegio Militar, al que se le comentó sobre la tensa situación en Campo de Mayo y sobre los deseos puntuales del general Álvarez, haciendo hincapié en que este último no aceptaría recibir órdenes del Estado Mayor Revolucionario, haciendo valer su antigüedad en el grado (por este motivo el general Uriburu procuró presionarlo radiotelegráficamente para que decline su actitud, con escaso éxito).

Situaciones como las relatadas anteriormente en la Escuela de Artillería se repitieron en otras unidades militares, fijando un denominador común: bajo grado de adhesión al golpe de Estado, tensión interna, falta 
de información, o desconexión entre el E. M. -estado mayor-y las tropas e improvisación en la toma de decisiones.

\section{LOS MILITARES GOLPISTAS, SUS ROLES Y FUNCIONES}

La organización del Estado Mayor incluía en su primera versión como máxima autoridad a su Comandante en Jefe, teniente general José F. Uriburu, y a un ayudante a designar (figura en el documento de puño y letra: "se designará”). ${ }^{17}$ El Estado Mayor integrado por el coronel José Mayora y diferentes secciones a cargo de aspectos relativos a la organización del movimiento: la 1ra. Sección, al mando del teniente coronel Alvaro Alsogaray, mayor Miguel Mascaró, como así también el capitán Juan D. Perón (Halperin Donghi, 2004) ${ }^{18}$ y Carlos Gay (en el caso de otro teniente coronel en la sección figura también de puño y letra: "se designará"; cabe destacar que en otra versión del mismo documento figura designado en la 1ra. Sección el teniente coronel Adolfo Espíndola, (Espíndola, 1930) ${ }^{19}$ pero con un signo de interrogación en tinta. Finalmente se confirmaría su participación en el movimiento golpista). Dicha sección se encargaría de todos los aspectos referidos a las operaciones militares por encarar.

Merece destacarse que en la primera versión del listado que conformaría la cúpula que dirigiría el estallido golpista no se mencionaba al teniente coronel Juan N. Tonazzi (quien ya se había entrevistado, junto al teniente coronel Espíndola, con el general Uriburu en julio de 1930, pero cuya participación al parecer despertaba algunas dudas). El oficial Tonazzi afirmaba en sus escritos ${ }^{20}$ que fue confirmado en la inminencia del levantamiento por el mismo general Uriburu e incorporado al Estado Mayor Revolucionario, formando incluso parte de la comitiva (en automóvil) junto al teniente coronel J. M. Sarobe, el 6 de septiembre de 1930. No resultaba un dato menor que Sarobe hombre de extrema confianza de Agustín P. Justo, fuera quien le confirmó que el golpe de Estado se realizaría ese día, fijando un horario y lugar de encuentro. El oficial Juan Tonazzi que había sido desplazado por el Director del Colegio Militar Francisco Reynolds (h.) por su estrecha colaboración con el anterior, Director Luis J. García (Etchepareborda, 1957; Orona, 1965), fue recompensado luego por sus servicios y lealtad durante el gobierno de Justo siendo designado a cargo de la Dirección de dicha institución a partir del 4 de junio de 1936 (Garcia Enciso, 1970).

Las fuerzas a movilizar se organizaron del siguiente modo. Las tareas de la 1ra. Sección fueron: redactar el Plan General de Operaciones, incluir la forma en que se tomaría la persona del actual presidente (vicepresidente, ministros, jefe de policía, jefes de unidades, grupos o batallones no adheridos) y definir su lugar de residencia o encarcelamiento (aclarándose entre 2 o 3 posibles). Se debían determinar previsiones sobre posibles fracasos, sobre las fuerzas civiles no comprometidas, sobre el sistema de correspondencia y clave, etc. Se dejó expresado que, para la correcta ejecución del Plan de Acción, se debían reunir adherentes, organizar su registro y movimiento de tropas, preparar cartografía necesaria, como así también cuestiones relativas a previsiones sobre comunicación. La 2da. Sección estuvo bajo el mando del teniente coronel Molina, Mayor Angel Solari, Ramírez, de Allende y Urbano de la Vega y a cargo del reclutamiento de elementos (en otra versión del mismo documento se incluye en la 2da. Sección al capitán Franklin Lucero con un "Si" agregado de puño y letra (confirmado en mayúscula y en tinta). La 3ra. Sección estaba integrada por un Jefe del Servicio Sanitario y de Administración, cuyos nombres no figuran, y en el documento se aclara de puño y letra: "se designarán". Esta sección tuvo a su cargo todos los aspectos referidos al área de servicios y apoyo al resto de las secciones. La sección de informaciones figura en blanco (en una versión posterior se incluyen de puño y letra, en lápiz y luego en tinta, al teniente coronel Pedro Pablo Ramírez, capitanes Jose Pipet y Ricardo Mendioroz). Finalmente se designó en la denominada Sección Especial a los tenientes coroneles (R) Emilio Kinkelin y Tesandro Santa Ana a cargo de las acciones políticas y sociales, propaganda y difusión, etc. (Scenna, 1980). La sección de informaciones debía proporcionar al E.M. -Estado Mayor- noticias e informes para la preparación y ejecución del Plan General, coleccionar artículos de prensa para justificar el 
movimiento, depurar y analizar las noticias sobre el movimiento y la ejecución de misiones. La 3ra. Sección organizó elementos civiles (aclarando que estarían unidos a las acciones de la 1ra. Sección).

El joven oficial Juan Domingo Perón manifestó que había un poco de interés y egoísmo en estas acciones y designaciones. Opinó además que los altos oficiales Molina y Alsogaray querían ser únicos y combatían la intromisión de todo hombre que pudiera suplantarlos, como lógicamente hubiera sucedido en el caso de que algunos jefes capaces hubieran ingresado decididamente a la agrupación. Eran, según sus expresiones, terriblemente celosos y trataban de esconder al general, con pretexto de asegurarlo, de manera que nadie sino ellos pudieran llegar a él. Se rescatan además algunas impresiones al respecto, donde para él estas designaciones no sólo implicaron un desplazamiento de muchos oficiales idóneos, sino también reflejaron que el movimiento estaba dirigido por incapaces que lo llevarían al fracaso. El teniente coronel Descalzo se lamentó, por ejemplo, porque desde el Estado Mayor "revolucionario" no le habían dado al coronel Fasola Castaño (militar de gran prestigio, capacitado y de acción, según calificativos del mismo Juan D. Perón) una función a la altura de su capacidad. Afirmó además que el seis de septiembre "el coronel Fasola estaría allí en el mejor lugar, para el caso de que pudieran herir o matar al general Uriburu, servir de E. M. al general Justo que tomaría el mando". 21

Las cualidades de liderazgo militar, niveles de apoyo castrense y capacidad de mando quedaron demostradas el mismo 6 de septiembre. El día del alzamiento el general Uriburu -a pesar de ser un militar muy respetado por su trayectoria dentro del ejército-, desde la localidad de Gral. San Martín, no logró con éxito incitar por radio al general Álvarez para que iniciara la marcha con sus tropas desde Campo de Mayo, y por este motivo se comisionó al teniente coronel Alsogaray (amigo del anterior e integrante destacado del Estado Mayor "Revolucionario") a que se dirigiera a Campo de Mayo, con resultados negativos. ${ }^{22}$ Entre sus partícipes se afirmó con pena que la revolución había terminado, ya que no sólo Campo de Mayo se manifestaba a favor del gobierno, sino que dos Regimientos en Capital se sumaron a la posición legalista. Esta situación demostró - para algunos historiadores - no sólo la verdadera ineptitud de Uriburu en la organización de la conjura, sino que también dejó en evidencia el escaso nivel de apoyo castrense que despertaba el levantamiento, algo que justificó la necesaria inclusión de civiles armados al mismo (Amaya, 1993).

A pesar de los obstáculos encontrados, aquel 6 de setiembre por la mañana el coronel Reynolds, a cargo del Colegio Militar, ${ }^{23}$ procedió a arengar a los cadetes. Se distribuyó la munición, fijando como primer objetivo la toma del cuartel de policía de San Martín, junto a la intervención del telégrafo nacional y provincial. Se procedió además a la requisa de vehículos y a la distribución de armamentos entre civiles y universitarios. Según recuerda Bautista Molina, el general Uriburu contó con una escolta de 40 hombres del Regimiento Nro. 2 y de la Escuela de Comunicaciones. La columna se organizó del siguiente modo: a la vanguardia, el mayor Gallo con una punta de caballería, una sección a cargo del capitán Mittelbach, una punta de infantería y tres grupos de fusileros; en la cabeza, una sección infantería y una de artillería. El grueso contó con la infantería del Colegio Militar bajo las órdenes del mayor Sosa Molina, además de una batería de artillería y una compañía de ingenieros. La agrupación de comunicaciones estuvo al mando del teniente coronel Rocco y el Regimiento I de Caballería bajo el mando del teniente coronel Parker. A las ocho de la mañana Botana telefoneó desde el Colegio Militar a la redacción ordenando activar las sirenas del local de Crítica. Ese día el tiraje del diario fue de 438.811 ejemplares bajo el titular: "Revolución” (Saitta, 2013).

El teniente coronel Iruzta relató, en el documento titulado "Juicio sobre los acontecimientos ocurridos el 6 de setiembre en el regimiento 7 de infantería con asiento en la ciudad de La Plata”, ${ }^{24}$ que llegado el expresidente al Regimiento procedió a entregar su renuncia al mayor Chinchurrieta, dándose por detenido y solicitando protección y albergue por encontrarse enfermo. Ante esta situación se procedió a darle alojamiento y todo tipo de comodidades, para luego despachar los telégrafos correspondientes, detallados a continuación. Siendo las 22:55 del seis de septiembre se envió un telegrama ${ }^{25}$ desde el Regimiento 7 con destino al presidente de la Junta de Gobierno Provisorio, con el siguiente texto: "Sr. Irigoyen encuéntrase 
detenido cuartel, habiéndome hecho entrega renuncia. Espero órdenes". Una hora más tarde se respondió una orden del presidente del gobierno provisorio bajo el siguiente telegrama; "Ponga inmediatamente en libertad al Sr. Hipólito Yrigoyen, dele toda clase de garantías y asegúrelas bajo su responsabilidad, poniéndose a sus órdenes para conducirle donde desee, recoja texto renuncia y comuníquela por telégrafo"; firmado por el teniente coronel Savio (Ministro del Interior). Treinta minutos después y siendo ya el día 7 de setiembre se expresa desde el Regimiento Nro. 7: "Contestando su comunicación de la fecha, transcribo texto renuncia que dice así: Ante los sucesos ocurridos, presento en absoluto la renuncia del cargo de presidente de la Nación Argentina. Dios guarde a Ud., firma Hipólito Yrigoyen” (Gutierrez de Miguel, 1930).

La conspiración Uriburista había logrado así su objetivo inicial, poner fin con un golpe de Estado disfrazado de revolución al gobierno encabezado por el caudillo radical elegido por voto popular dos años atrás. De esta manera se dio paso a otro gobierno que poco tendría de provisional orientado a sentar las bases de un nuevo orden que atentaría contra los pilares mismos del sistema democrático.

\section{LAS DERIVACIONES Y SUS IMPACTOS}

Una vez alcanzado el doble objetivo de los golpistas -ante la inacción generalizada de las tropas legalistas-, el desplazamiento de Yrigoyen y la toma del poder, se realizaron los juramentos de rutina. Estos fueron encabezados por los integrantes del gabinete del gobierno provisional a cargo del general José F. Uriburu. En procura de rodearse de los militares de su mayor confianza, nombró inmediatamente como secretario de presidencia al teniente coronel Bautista Molina y al teniente coronel Alvaro Alsogaray ${ }^{26}$ al frente de la Casa Militar $^{27}$ (a partir del 7 de septiembre de 1930 con despachos y oficinas dentro de la Casa de Gobierno). Así se continuó con una línea de acción ya ideada y aplicada con anterioridad: premiar la lealtad y cercanía de unos pocos despertando la crítica y oposición de muchos.

El escaso nivel de apoyo y acatamiento que evidenció el alzamiento, aquel 6 de septiembre de 1930, llevó prontamente a solicitar a las unidades militares del país y a oficiales informes por escrito sobre el rol adoptado aquel día. En pos de alcanzar ese objetivo, los hombres de confianza de Uriburu (Molina y Alsogaray) elevaron (desde el 15 de septiembre de 1930 al 16 de diciembre de 1931) las Circulares Reservadas Nro. 1, Nro. 2 y Nro. 3. En la primera de ellas se incluía un cuestionario ${ }^{28}$ cuyo objetivo era recabar información sobre la actitud asumida por los militares antes y durante el alzamiento. En las restantes circulares, se pretendía ampliar la información recopilada solicitando informes detallados desde diferentes unidades militares, como así también desde los jefes al servicio de cada una de ellas. El cuestionario solicitaba datos precisos: nombre y apellido del oficial, grado y arma, unidad de destino al 6 de septiembre de 1930, la fecha de incorporación al movimiento, el oficial que había solicitado su adhesión, el detalle de su actividad en beneficio del movimiento, el rol de la unidad de la que formaba parte aquel día, los inconvenientes que se tuvieron para ejecutar las órdenes impartidas, las iniciativas personales efectuadas y finalmente las anécdotas interesantes, actos de valor que se desarrollaron ese 6 de septiembre.

Estas acciones se justificaban además por la existencia de voces de disidencia castrense de varios oficiales superiores, como los tenientes coroneles José María Sarobe y Bartolomé Descalzo -quienes acompañaron al general Justo en todo momento- que, si bien coincidían con los uriburistas en desplazar a Yrigoyen del gobierno a través de una acción militar, en otros planos mostraron sus claras y contundentes diferencias. La mayoría de estos militares justistas rechazaban el proyecto uriburista de reforma institucional, que incluía la eliminación de toda representatividad civil canalizada desde los partidos políticos tradicionales. Para ellos, en cambio (desde el programa ideado y difundido por el teniente coronel José María Sarobe), Yrigoyen debía ser reemplazado en primera instancia por otro civil, el presidente del Senado -radical antipersonalista- y no por el jefe militar del alzamiento golpista. 
Estas reformas tan resistidas y criticadas fueron impulsadas además por civiles muy cercanos al general Uriburu, tal fue el caso de Juan Carulla o Carlos Ibarguren (Segovia, 2006). ${ }^{29}$ El 7 de marzo de 1931, insistiendo con este mismo objetivo, en La Nueva República se publicó un extenso manifiesto sobre la formación de los poderes públicos, en el que las ideas corporativistas cobran nuevo impulso, como ensayo de la organización de un gobierno sin recurrir al sufragio universal, sin elecciones, partidos ni comités, esbozando una nueva constitución en la parte orgánica, en la que el voto se restringe al ámbito municipal.

Superadas las ambivalencias iniciales, a pesar de las críticas y la creciente oposición que despertaban estas propuestas, el 18 de junio de 1931 el general Uriburu dio a conocer el manifiesto de reforma constitucional. El Ministro Matías Sánchez Sorondo había negociado con las fuerzas políticas que reformarían la constitución, definiendo además el alcance que tendría esa reforma. Las bases fijadas a tal efecto reconocían la necesidad de que dicha modificación debía ser declarada por el Congreso y que se sujetaría a fortalecer la autonomía provincial, armonizar el sistema tributario federal, establecer el funcionamiento autónomo del Congreso y asegurar la independencia de la judicatura.

A pesar de los esfuerzos por mostrar al golpe de 1930 como una contundente y necesaria revolución, sus debilidades y flaquezas quedaron de manifiesto al conformarse el gobierno provisional. El apoyo en particular- al proyecto corporativista del general José Félix Uriburu y a su gobierno -en general- no resultó a la luz de los hechos extendido y generalizado entre las FF. AA., ya que el 27 de diciembre de 1930 se abortaba una sublevación de 34 suboficiales en la provincia de Córdoba. Luego, el 20 de febrero de 1931, fue descubierta una acción contrarrevolucionaria dirigida por el general Severo Toranzo, y el 20 de julio se produjo un alzamiento radical en la provincia de Corrientes encabezado por el teniente coronel Gregorio Pomar (Garcia Molina y Mayo, 1986). ${ }^{30}$ Posteriormente, el 27 de agosto, se descubrió un conato revolucionario en Tucumán, y el 3 de Enero de 1932 se realizó un levantamiento cívico-militar en La Paz, provincia de Entre Rios. ${ }^{31}$ Inaugurada una etapa caracterizada por elecciones fraudulentas, asumirá el 20 de febrero de 1932 la presidencia de la república el general Justo con bases de apoyo más sólidas, confirmando así las ambiciones políticas de quienes idearon, propiciaron y encabezaron el golpe bicéfalo de 1930 .

\section{Conclusiones}

La planificación del golpe de Estado de 1930 estuvo envuelta en un marco de incertidumbre, dudas y diferencias que acompañaron siempre a sus promotores (desde sus comienzos y primeras reuniones conspirativas), pero estas nunca fueron interpretadas como un serio obstáculo lo suficientemente importante como para impedir su ejecución. Los documentos analizados demuestran que existieron siempre inquietudes entre sus líderes y máximos protagonistas acerca del nivel de acompañamiento y adhesión militar real que tendría el movimiento septembrista. Esta cuestión se verificó el mismo 6 de setiembre a partir de la formación de una débil columna que avanzó temerosa hacia la Casa de Gobierno; la misma era integrada mayormente por cadetes del Colegio Militar y efectivos de la Escuela de Comunicaciones (entre otras unidades menores, que en total no superaban los 1500 hombres). En las FF. AA. la Marina se mantuvo prácticamente ajena a dicho acontecimiento: la inmensa mayoría de los efectivos de Campo de Mayo se mantuvo leal al orden constitucional y al gobierno elegido por el pueblo y no salió de sus cuarteles. Por su parte la aviación acompañó tímidamente el levantamiento desde la Base Aérea de El Palomar y en menor medida desde la base con asiento en Paraná, movilizando en total sólo 20 aeronaves aproximadamente. ${ }^{32}$

La conformación del Estado Mayor, liderado por los tenientes coroneles Juan B. Molina y Álvaro Alsogaray (y otros altos oficiales de confianza del general Uriburu), despertó críticas y objeciones de todo tipo. Disminuyó así la cohesión y unidad de quienes dirigirían y acompañarían el alzamiento. Muchos oficiales fueron desplazados y otros no fueron contemplados en funciones acordes a su rango, experiencia y trayectoria. Prevalecían, pues, ambiciones de poder, egoísmos personales y desconfianzas que hicieron que unos pocos se 
autoproclamaran como líderes y jefes exclusivos del alzamiento. Uriburu no contempló -o bien no le interesó considerar- las consecuencias que provocarían dichas designaciones (situación similar que luego se reiteraría al tomar el control gubernamental y definir la conformación de su gabinete), sin asegurarse o preocuparse por el nivel de apoyo o adhesión que despertaban entre la oficialidad tanto Alsogaray como Molina (ente otros integrantes del Estado Mayor).

Los máximos responsables del Estado Mayor "Revolucionario" -los tenientes coroneles Bautista Molina y Álvaro Alsogaray- no poseían destacadas cualidades de liderazgo militar en el seno del ejército, aspectos estos importantes al momento de pretender despertar entre la alta oficialidad el nivel de confianza y apoyo necesarios que permitieran garantizar un mayor nivel de acompañamiento, lealtad y compromiso durante el golpe de Estado y luego del mismo. Desaparecido el factor aglutinante del alzamiento en torno a la necesidad de la destitución de Yrigoyen, emergieron las fisuras y las deserciones. La heterogeneidad y las contradicciones presentes entre quienes acompañaron con mayor o menor nivel de protagonismo el alzamiento se hicieron evidentes con total nitidez y contundencia luego de producido el mismo. Así se fue retirando progresivamente el apoyo, tanto de civiles como de militares, como así también de gran parte de la prensa adherida inicialmente al golpe, anticipando el fin de la breve experiencia uriburista.

Existieron ambiciones de poder personal, intereses particulares y proyectos políticos antagónicos que marcaron claras diferencias, roces y divergencias. Se puede afirmar además que se partió de la falsa premisa de que el malestar existente en las filas del Ejército (y extensivamente en gran parte de las FF. AA.) por la gestión y estilo de gobierno particular del viejo caudillo radical Hipólito Yrigoyen sería causa única y fundamental para garantizar en sí mismo el acompañamiento masivo de las FF. AA. al objetivo golpista (y por extensión al naciente gobierno provisional encabezado por el líder "revolucionario"). En la medida que avanzaba la conspiración golpista, esta aspiración inicial se fue diluyendo y en contraposición, al momento del alzamiento, surgió que gran parte de la alta oficialidad no se sumaba al movimiento ya que se manifestaba como legalista y aliada al gobierno. Por este motivo muchos oficiales se definían profesionalmente como defensores del Estado de derecho y de la Constitución, o bien adoptaron una actitud pasiva ante los hechos sin fijar una posición clara. Esta última acción, si bien colaboró indirectamente con el triunfo del alzamiento, no demostró ser una expresión de apoyo genuino al proyecto uriburista ni a su gobierno.

El gobierno no declaró el Estado de sitio ni la ley marcial, sino que fusiló, censuró y reprimió a la oposición, dando forma a una dictadura no deseada por la mayoría, mermando así sus apoyos originales. Además, según Romero (1992), el general Uriburu habló en distintos foros (mayormente militares) abominando de la democracia, reclamando una reforma institucional de fondo y predicando las ventajas del corporativismo, pero su poder y habilidad política eran escasos. Los nacionalistas y conservadores se fueron distanciando del gobierno a medida que crecía la influencia del general Justo, aglutinándose en una única fuerza capaz de imponer por el fraude "patriótico" un régimen neoconservador (Ternavasio, Sabato, De Privitellio, y Persello, $2011)^{33}$ que se opusiera eficazmente a la oposición política y sindical local, como así también a la influencia del socialismo, entendidos todos como amenazas a una patria unida y a una sociedad jerarquizada.

Ante la formación del gobierno provisional algunos contemporáneos expresaban incluso lo desconcertante que era que un militar estuviera a cargo del mismo. Se traicionaban así los deseos y sentires de muchos que vieron la necesidad de un desplazamiento forzado del gobierno radical para un inmediato llamamiento a elecciones (negado en un primer momento por Uriburu). Con cierta ingenuidad se afirmaba además que no existía peligro de dictadura militar, ya que el gobierno estaba integrado mayormente por civiles -claros exponentes del conservadorismo más tradicional-. Algunos lo definieron como gobierno cívico-militar, régimen militar o bien como una dictadura de carácter personalista: lo cierto es que si bien no fue una junta integrada exclusivamente por miembros representativos de las FF. AA., fue un gobierno de facto que se extendió por diecisiete meses. El gobierno de Uriburu cobijó en su seno, además, a militares de su máxima confianza (pero duramente criticados por otros altos oficiales), como el teniente coronel Bautista Molina, designado Jefe de la Secretaría de la Presidencia, y el Teniente Coronel Álvaro Alsogaray al frente de la 
Casa Militar (dejando de lado a otros como el coronel Reynolds). Entre otras funciones dichos militares se abocarían a indagar a todos los oficiales del ejército sobre su rol asumido en la jornada del 6 de septiembre de 1930.

\section{ReFERENCIAS}

Amaya, A. (1993). 6 de septiembre. Ensayo Histórico-Político-Jurídico. Bs. As. Jorge Baudino Ediciones.

Botana, N. (1977). El orden conservador: la politica argentina entre 1880 y 1916. Buenos Aires: Sudamericana.

Buchrucker C. (2013). Las formas autoritarias del nacionalismo y el conservadurismo latinoamericanos (Tesis de Doctorado). Facultad de Ciencias Económicas, Universidad de Buenos Aires.

Carrera N. I. (2018). Los hechos armados en la primera mitad de los años 30. En X Jornadas de Sociología de la UNLP (5 al 7 de diciembre de 2018). Universidad Nacional de La Plata, Facultad de Humanidades y Ciencias de la Educación, Departamento de Sociología. Ensenada, Argentina.

Cattaruzza, A. (2016). Las culturas políticas en la Argentina de los años treinta: algunos problemas abiertos. Anuario del Instituto de Historia Argentina, 16(2).

Dalmazzo, G. (2010). El primer dictador. Uriburu y su época. Buenos Aires: Vergara.

Mc Gee Deutsch, S. (2005). Las derechas: la extrema derecha en la Argentina, el Brasil y Chile, 1890-1939. Buenos Aires: Universidad Nacional de Quilmes Editorial.

Miranda, S., González Prieto, C. y Mc Gee Deutsch, S. (1993). Las ligas patrióticas. Revista de Ciencias Sociales (Cl), 2, 54-72.

Devoto, F. (2002). Nacionalismo, fascismo y tradicionalismo en la Argentina moderna: una historia [Vol. 1]. Buenos Aires: Siglo Veintiuno Editora Iberoamericana.

Devoto, F. y Madero, M. (1999). Historia de la vida privada en la Argentina. Buenos Aires: Taurus.

Etchepareborda, R. y otros (1958). "La crisis de 1930". En Revista de historia. Bs. As. S/E.

Etchepareborda R., Bagú, S., Ortiz, R. M., y Orona, J. V. (1986). Crisis y Revolución de 1930. Buenos Aires: Hyspamérica.

Espigares Moreno, J. M. (1933). Lo que me dijo el general Uriburu, Durruty y Kaplan. Buenos Aires: S/E.

Feldman, H. (2008). El derrocamiento de Hipólito Yrigoyen: acontecimiento, vacío y lenguaje. EIAL: Estudios Interdisciplinarios de America Latina y el Caribe, 19(2), 91-118.

Finchelstein, F. (2002). Fascismo, liturgia e imaginario: El mito del general Uriburuy la Argentina nacionalista. Buenos. Aires: Fondo de Cultura Económica.

García Enciso, I. (1970). Historia del Colegio Militar de la Nación. Buenos Aires: Círculo Militar.

Garcia Molina, F. y Mayo, C. (1986). Archivo del general Uriburu: autoritarismo y ejército. Bs. As. C.E.A.L.

González Alemán M., "El 6 de septiembre de 1930 en Argentina: un golpe de Estado invirtió revoluciones" Nuevo Mundo Mundos Nuevos [Online], Conferencias, publicada el 18 de mayo de 2007, consultado el 21 de noviembre de 2015. URL: http: //nuevomundo.revues.org/5385; DOI: 10.4000 / nuevomundo.5385.

Gutiérrez de Miguel, V. (1930). La Revolución Argentina. Relato de un testigo presencial. Buenos Aires: CIAP.

Halperin Donghi, T. (2004). La República imposible (1930-1945). Buenos Aires: Emecé.

Orona, J. (1965). La logia militar que enfrentó a Hipólito Yrigoyen. Buenos Aires: Ed. Leonardo.

Orona J. (1966). La revolución del 6 de septiembre. Buenos Aires: Ed. López.

Potash, R. (1985). El Ejército y la Política en la Argentina -1928/1945 de Yrigoyen a Perón-. Buenos Aires: Hyspamérica.

Reynolds, F. (1969). La revolución del 6 de septiembre de 1930. Buenos Aires: Ed. Colombo.

Rock, D. (1992). El radicalismo argentino (1890-1930). Buenos Aires: Amorrortu Ed. 
Rock, D. (1993). La Argentina autoritaria -Los nacionalistas, su historia y su influencia en la vida pública-. Buenos Aires: Ariel.

Romero, J. L. (1992). Las ideas politicas en Argentina. Buenos Aires: FCE.

Romero, L. A. (1969). Los golpes militares. 1812-1955. Buenos Aires: Ed. C. Pérez.

Rouquié, A. (1985). Poder militar y sociedad politica en la Argentina - hasta 1943-. Buenos Aires: Emecé.

Saitta, S. (2013). Regueros de tinta, el diario Crítica en la década de 1920. Buenos Aires: Siglo XXI.

Segovia, J. F. (2006). El modelo corporativista de Estado en la Argentina, 1930-1945: entre el derecho, la política y la ideología. En Revista de historia del derecho.

Scenna M. A. (1980). Los Militares. Buenos Aires: Ed. de Belgrano.

Tato, M. I. (2004). Viento de fronda: liberalismo, conservadurismo y democracia en la Argentina, 1911-1932. Buenos Aires: Siglo XXI Ed.

Ternavasio, M., Sabato, H., De Privitellio, L., y Persello, A. V. (2011). Historia de las elecciones en la Argentina. Buenos Aires: El Ateneo.

Viale Ledesma, S. (1931). 6 de septiembre, el pueblo, el ejército y la revolución. Buenos Aires: Ediciones Mercurio.

\section{Notas}

1 Los horarios y textos incluidos en los radiotelegramas reflejaban un creciente nivel de tensión entre ambos generales. Siendo las 11:50 del 6 de septiembre de 1930, y luego de cuatro horas de comunicaciones, el general José F. Uriburu expresaba que la Escuela de Infantería no podía ser un obstáculo e intimaba luego al general Álvarez a plegarse al movimiento y que, de no hacerlo, se dejaría a las tropas de Campo de Mayo atrás, argumentando que no eran necesarias para llevar adelante la acción. Ver AGN/FJFU Leg. Nro. 2594 S/F -Anexos 1 a 18-.

2 Los militares y civiles incluidos en el presente artículo no se agotan en el listado aquí analizado, ya que el mismo ha sido definido como una primera aproximación a quienes lideraron en gran medida dicho acontecimiento desde diferentes roles asumidos.

3 Recuerda Bautista Molina que, en relación a estas reuniones, se habían concretado varias entrevistas en 1929 con el teniente coronel Alsogaray, que luego sumaron al general Uriburu. Muchas de ellas tuvieron lugar en la sede del jockey Club y la última se realizó en la casa del general Justo. En AGN/FJFU Leg. Nro. 2594 Folios Nro. 47/48.

4 Durante la primera Guerra Mundial, Carulla se alistó en el Ejército Francés en el área médica y durante su servicio se convenció de que la izquierda política no había hecho nada para ayudar al esfuerzo de guerra, llevando a su abandono del anarquismo. Mientras estuvo en Francia se convirtió en un firme defensor de Action française y esto fue decisivo en sus opiniones políticas, cuando regresó a su tierra natal. En Argentina se asoció con los seguidores de Leopoldo Lugones y, junto a Rodolfo Irazusta, ayudó a fundar y editar la revista La Nueva República en 1927. También produjo su propia revista: Bandera Argentina.

5 El general Uriburu estuvo suscripto tempranamente a muchas de ellas como La Fronda, en 1925 a La Voz Nacionalista y en 1927 a La Nueva República.

6 Ante lo que era percibido como una amenaza socialista por parte de las FF. AA., por agrupaciones nacionalistas y políticos conservadores, el general Uriburu afirmaba tempranamente, en su escrito titulado Socialismo y defensa nacional, que el Ejército era la única institución capaz de oponerse eficazmente a las fuerzas organizadas de la sociedad que actuaran desde un impulso revolucionario. Desde su propia lógica, se identificaba al socialismo como un peligroso enemigo que debía ser enfrentado exclusivamente por el accionar represivo, separando claramente la órbita civil y política de la estrictamente militar.

7 El general Uriburu adquirió prestigio profesional entre sus camaradas cuando se hizo cargo en 1923 de la creada Inspección General del Ejército. Ocupa este puesto, quizás creado bajo su propia iniciativa y propuesta directa, para diferenciar la labor ministerial de la estrictamente militar. El general Justo (ministro de guerra del gobierno radical), después del dictamen de su secretario, el mayor José M. Sarobe (pieza clave durante la gestación del alzamiento cívicomilitar de 1930, militar de confianza de Justo y de enlace con el sector uriburista), rechazó sus propuestas en diversas ocasiones. José F. Uriburu a pesar de los lazos de amistad que lo unían al ministro pidió y obtuvo su relevo. En 1926 abandona el cargo, fastidiado por las negativas a sus pedidos y a los recortes presupuestarios impuestos desde el ministerio de Guerra. Se anticipaban así las diferencias presentes entre los generales Justo y Uriburu. Ver Orona (1966).

8 En AGN/FJFU Leg. Nro. 2594/Folio 23.

9 Ver diario Critica, Rollo 114, Caja S/Nro., del 24/8/1930 al 21/9/1930, Biblioteca Nacional. 
10 La prensa opositora no confluía en un mismo campo político-ideológico, sólo coincidía, desde diferentes percepciones y tendencias, en accionar contra el gobierno de Hipólito Yrigoyen: algunos diarios, como La Nación, de orientación conservadora, otros como La Vanguardia, desde una orientación claramente Socialista, o Crítica con un formato novedoso para la época y orientado a un público amplio. Estos diarios aportaron una mirada diferenciada sobre los hechos en cuestión y, paradójicamente, fueron luego censurados por el régimen que tomó el poder como consecuencia del golpe.

11 Debe mencionarse que esta influencia se hizo cada vez más notoria en los días previos al golpe de Estado y encontraba claras diferencias en relación al tiraje y presencia nacional de diferentes matutinos, como lo fueron La Nación y La Prensa en primer lugar, seguidos de Vanguardia y Crítica con un impacto más reducido, circunscripto mayormente al ámbito de la Capital Federal. Para ampliar ver Saitta (2013). En relación a la incidencia castrense no debe soslayarse la influencia de revistas de circulación interna como la publicación de la Revista Militar del Círculo Militar (de carácter mensual).

12 Si bien el general José F. Uriburu desconfiaba de los políticos y rechazaba sumar a los civiles en toda acción contra el gobierno de Yrigoyen, no se impidió que un selecto grupo de civiles, entre los que se encontraba Juan Carulla, lo contactara tempranamente desde 1928 procurando convencerlo de la necesidad de llevar adelante un levantamiento cívico-militar que se concretaría dos años después. Su linaje, trayectoria militar y su paso por el Congreso le dieron a José F. Uriburu la posibilidad de contar con apoyo de selectos grupos de la alta sociedad que frecuentaban en el Jockey Club, de altos oficiales que concurrían al exclusivo Círculo Militar como así también de civiles que se sentían atraídos por su pensamiento político y su estirpe prusiana.

13 Para González Alemán (2007), la revolución uriburista terminó siendo un golpe puramente militar, entendido y llevado adelante como un medio necesario para hacerse del poder con el objetivo de terminar con el sistema democrático liberal. Por otro lado - para la autora- la revolución civil fue entendida como un mito movilizador que poseía un carácter purificador orientado a legitimar la acción del pueblo contra la tiranía Yrigoyenista (visualizado como un dictador, anticonstitucional y responsable del caos que sufría el país).

14 El general Francisco Reynolds (padre del coronel del mismo nombre que acompañó a José F. Uriburu en el alzamiento golpista de 1930) fue director de dicha institución entre los años 1897 a 1904 y de 1905 a 1906. Su segunda administración se vio convulsionada por el estallido de la revolución radical en la que participó su hijo siendo un joven oficial, aliado en aquel entonces al caudillo Hipólito Yrigoyen. Procurando evitar que se involucrara en hechos políticos su padre lo forzó a aceptar una licencia para viajar a Europa y unirse por dos años al ejército francés (país donde su padre estaba comisionado), hecho que nunca se concretó. Aquel hombre, proveniente de una tradicional familia conservadora, que lideró al único cuerpo militar organizado contra un gobierno constitucional por primera vez en la historia nacional, se encontrará en 1930 no sólo distanciado de los deseos paternos de verlo alejado de la política, sino también de la amistad que supo cosechar con Hipólito Yrigoyen. Ver García Enciso (1970).

15 Hasta la noche de ese día no existía en Uriburu un convencimiento pleno del éxito de la "revolución”. Ver Scenna (1980).

16 En sus inicios el Colegio Militar de la Nación procuró, desde el ingreso, el reclutamiento y posterior formación de sus jóvenes cadetes -en general de clase media y muchos de ellos becados-, la mayor profesionalización posible, entendiéndose esta como un mecanismo de conformación de un poder militar independiente del poder civil y de toda injerencia externa, incluso la política. Así, en sus estudios cursarían mayormente materias propias de su carrera, con el objetivo de -como afirma Rouquié- "militarizar al militar" bajo una clara y directa influencia prusiana, donde prevalecía la disciplina y se exaltaba la ritualización, pero donde la obediencia y la verticalidad del mando no resultaban sinónimo de aceptación de liderazgos forzados o impuestos, ni como justificación a la alteración del orden establecido constitucionalmente. A pesar de ello, es de destacar que esta institución comienza a anticiparse como un escenario privilegiado para manifestaciones adversas al gobierno de turno. Se puede dar el ejemplo del entonces coronel Agustín P. Justo que en carácter de Director (entre los años 1915 a 1922) de dicha casa de estudios, y ante una mirada desconfiada y permisiva del gobierno, hace participar a los cadetes en un homenaje a Bartolomé Mitre -figura fundadora y representativa del régimen conservador combatido por la UCR y por Hipólito Yrigoyen en particular-.

17 Ver AGN/FJFU, Legajo Nro. 2582, Folio 40 y Ss.

18 La participación de Juan D. Perón no fue muy entusiasta, ni comprometida según sus propias afirmaciones: “... Al día siguiente fui a visitar a mi querido amigo y primer capitán teniente coronel Descalzo (...) le dije 'Vea que el que preside la agrupación es el general Uriburu'. Él me contestó: 'Bien, tengo un gran concepto personal del general, pero ¿quiénes son los que lo rodean?’. Allí debí palidecer. Este hombre, por una natural intuición y con gran conocimiento de las cosas, me llevó al terreno donde debían sucumbir mis argumentos (...). Le contesté que por ahora estaban junto al general los tenientes coroneles Molina, Alsogaray y mayores Solari, Sosa Molina y otros. Allí fue donde me dio el golpe de gracia. Me dijo: 'Sosa Molina y Solari son buenos oficiales. Pero con los otros yo no voy ni a misa'. El teniente coronel Descalzo en un segundo me había dicho, lo que yo había necesitado dos meses para convencerme”. En Halperin Donghi (2004) p. 36

19 El teniente coronel Espíndola posee varias publicaciones en la Revista Militar, de consumo castrense. Entre ellas se pueden citar en la sección: Hagamos conocer nuestros conductores una defensa de un libro alemán publicado recientemente bajo el título Führertum -caudillaje/liderazgo-, colmado de alabanzas y relacionado con la figuras de San 
Martín y Bolívar [No queda claro si te trata del título de una publicación (si fuera así debe ir con comillas) o del nombre de una sección de la revista]. Ver: Adolfo Espíndola; Fürerthum. 1930. En Revista Militar, Nro. 354, pp. 1-6.

20 Ver AGN/FJFU Leg. Nro. 2583, Folio 38 y Ss.

21 Para profundizar ver Halperin Donghi (2004)

22 Debe contemplarse que el general Uriburu no se veía a sí mismo como un líder político o revolucionario. Poco antes de finalizar su mandato, en el mes de febrero de 1932, el general Uriburu confiere una entrevista al periodista José María Espigares Moreno del diario La Razón. En ella afirmó, ante la sorpresa del entrevistador, que él nunca había sido un revolucionario: "pienso que en realidad, técnicamente hablando, yo no he hecho una revolución, sino exactamente una operación de guerra, que era lo que convenía y lo que debía hacerse, y no una revolución sangrienta y bárbara indigna al país y de quienes la hemos llevado a efecto". En Espigares Moreno, J. M. (1933).

23 Alberto Viñas, quien en agosto de 1930 fue el ideólogo y director de la Legión de Mayo, recordaba con elocuente e ingenua nostalgia: “jamás olvidaré el espectáculo de aquella mañana gloriosa al ver salir en formación esa pléyade gallarda de futuros oficiales casi adolescentes que con sonrisas en sus labios abandonaban las aulas del Colegio Militar para entregar sus vidas (...) por el honor de la nación argentina”. En AGN/FJFU Leg.Nro. 2598/38.

24 Ver AGN/ FJFU Leg. Nro. 2598/11.

25 AGN/FJFU Leg. 2598/22.

26 En febrero de 1932 será designado como Inspector de Distritos Militares de la 2da. División del Ejército.

27 Este organismo funciona dentro de la Casa de Gobierno desde 1909, definiendo y ampliando sus funciones a partir del 28 de abril de 1916. Sus integrantes pertenecen mayormente a las Fuerzas Armadas, son muy próximos al gobierno, gozan de la absoluta confianza del Jefe de Estado y dependen directamente de él, recibiendo órdenes e instrucciones directas del presidente de la Nación. Se encarga además de regular el servicio de Edecanes, de la Comisaría de la Casa de Gobierno a cargo y de la seguridad del presidente de la república. El Jefe de la Casa Militar recibe dignatarios y altos funcionarios de Estado, acompaña además al presidente a todos los actos de Estado y se encarga de la custodia presidencial.

28 Entre los cuestionarios analizados figuran el del teniente primero Valette, el del coronel Juan Tonazzi, mayor Laprida Villanueva y Enrique Quiroga, los capitanes Denari, Félix Siddero, Juan Mocellini, Alberto Daguerre, Alberto Silva, los tenientes Javier de Verda, Adolfo Marsillach, Alberto de Oliveira Cesar, Carlos Aragon, Juan María Domínguez y Antonio Morey, teniente primero Emilio Lozay Eneas Colombo, el subteniente Julio Barredo, Alberto Ferro, el teniente de fragata Manuel Pardal, el civil Alberto Viñas, entre otros. Ver AGN/AGU Leg. Nro. 2594, Folio 14 y Ss.

29 Estas reformas, según Ibarguren -impulsadas y defendidas desde 1922-, tendían a entender y definir que en el Estado actuasen los representantes genuinos de los verdaderos intereses sociales, expulsando a los elementos identificados como parasitarios, a la burocracia de comité y al denominado funcionario caudillejo de parroquia. Para Carulla el programa de la revolución -ya anticipado en las propuestas de Rómulo Amadeo en 1922- se debía concentrar en tres grandes tareas: modificar el sistema electoral, reforzar los poderes del Estado para que no fueran presa de las oligarquías partidarias, y reformar la constitución, introduciendo nuevos principios ético-políticos, como ser la representación corporativa. Ver Segovia (2006).

30 Fue esta sucesión de acontecimientos, iniciados con el fracaso en las elecciones de 1931, la que precipitó una crisis interna en el gabinete y la "rendición” a las pretensiones del general Justo. Ver Garcia Molina, F. y Mayo, C. (1986).

31 Superando las percepciones originales de algunos dirigentes Socialistas como Nicolás Repetto, que entendieron en aquel momento que el motín liderado por Gregorio Pomar podría haber significado el comienzo de una guerra civil, se debe entender que los levantamientos se inscribieron en un contexto más complejo y de mayor envergadura, ya que no se circunscribieron solo a alzamientos de civiles y militares yrigoyenistas o legalistas contra golpistas, sino más bien a un clima de oposición política más profunda y amplia, que involucraba a parte de la clase obrera opositora en momentos donde resultaba generalizada y naturalizada la apelación al uso de armas y a la constitución de ciertas formas de reacción armada -aunque no necesariamente dirigidas a disputar el poder-. Existen numerosos hechos protagonizados por organizaciones autodenominadas "nacionalistas" que habilitaron y provocaron luego intervenciones federales, como fue el caso de la provincia de San Juan en 1934. De esta manera, las nueve conspiraciones y alzamientos armados de militares legalistas y militantes radicales opuestos a los gobiernos de los generales Uriburu y Justo encontraron sentido dentro de una lógica que superaba la simple oposición o contradicción antes mencionada. Ver Carrera (2018).

32 Para el teniente coronel Rottjer la revolución del 6 de septiembre atravesó un largo camino dificultoso; analizada desde un punto de vista estrictamente militar, se debe aceptar que si bien el núcleo original de fuerzas movilizadas era reducido, existieron órdenes que indicaban que varias unidades debieron quedarse en sus cuarteles, como fue el caso de los regimientos nros.2, 3 y 6, un batallón del regimiento nro. 1, una compañía de ametralladoras, dos escuadrones del regimiento de granaderos a caballo, un escuadrón de caballería de la escuela superior de guerra y la mayor parte de la Marina de guerra, del cuerpo de policías de la Capital Federal y de bomberos. Ver Revista Militar, Nro. 356, Septiembre 1930, BCM Código Nro. 33780.

33 Según Luciano De Privitellio (2011), esta etapa se caracterizó además por la desaparición del voto entendido como mecanismo eficaz de representar fielmente a la sociedad y para dar solución a las controversias políticas de la época. 
Anuario del Instituto de Historia Argentina, 2020, 20(1), Mayo, ISSN: 2314-257X

CC BY-NC-SA 